\title{
Super square carbon nanotube networks: mechanical properties and electric conductivity
}

\author{
V. V. Shunaev ${ }^{\dagger, 1}$, O. E. Glukhova ${ }^{1,2}$ \\ †vshunaev@list.ru \\ 'Saratov State University, Physical Department, 83 Astrakhanskaya St., Saratov, 410012, Russia
${ }^{2}$ I. M. Sechenov First Moscow State Medical University, Laboratory of Biomedical Nanotechnology, Trubetskaya St. $8-2$, \\ Moscow, 119991, Russia
}

Super square carbon nanotube (SSCNT) lattice is a class of CNT networks that have unique mechanical and electrical conductivity properties and can be applied in various modern devices. Two possible supercells of the SSCNT structure with minimal sizes of a "window" were obtained in the result of mathematical modeling. These supercells, called SSCNT-I and SSCNT-II, are distinguished by their topology and the number of non-hexagonal elements. On the basis of the analysis of stress-strain state curves, it was established that the structure SSCNT-I with a smaller number of defects was stronger. 2D films with experimental dimensions were obtained by translation of supercells SSCNT-I and SSCNT-II. The resistances of these films were calculated using the non-equilibrium Green function (NEGF) method: for SSCNT-I these values equaled $18.13 \mathrm{k} \Omega$ in the $\mathrm{Z}$ direction and $42.74 \mathrm{k} \Omega$ in the $\mathrm{Y}$ direction, for SSCNT-II $-65.86 \mathrm{k} \Omega$ in the $\mathrm{Z}$ direction and $60.17 \mathrm{k} \Omega$ in the Y direction. The better conductivity of the structure with supercells SSCNT-I along both directions can be explained by a less number of defects. Together with the better heat of formation and mechanical strength, it can be concluded that films composed of SSCNT-I are more suitable for application in electronic devices. Calculations show that the resistance of SSCNT films is higher than the resistance of CNT in 4-10 times, but they allow placing electrodes in both vertical and horizontal directions that may be important for their use in wearable electronics devices.

Keywords: carbon nanotube, super square networks, molecular modeling, conductivity.

УДК: 537.96537 .311 .31

\section{Суперсетки из нанотрубок с квадратными ячейками: механические свойства и электрическая проводимость}

\author{
Шунаев В. В. ${ }^{\dagger, 1}$, Глухова О.Е. ${ }^{1,2}$ \\ †vshunaev@list.ru
}

${ }^{1}$ Саратовский государственный университет, физический факультет, ул. Астраханская, 83, Саратов, 410012, Россия, ${ }^{2}$ Первый Московский государственный медицинский университет им. И. М. Сеченова, Лаборатория биомедицинских технологий, ул. Трубецкая, 8-2, Москва, 119991, Россия

Решетки из углеродных нанотрубок (УНТ) с квадратными ячейками - это класс сетей УНТ, который обладает уникальными механическими и электрическими свойствами проводимости и применяется в различных современных устройствах. Методами математического моделирования были получены две возможные суперячейки пленок из УНТ с квадратными ячейками с минимально возможными размерами «окна». Эти суперячейки, названные нами SSCNT-I и SSCNT-II, отличаются топологией и количеством негексагональных элементов. На основании анализа кривых напряженно-деформированного состояния установлено, что структура SSCNT-I, обладающая меньшим количеством дефектов, является более прочной. 2D пленки, соответствующие экспериментальным размерам, были получены трансляцией суперячеек SSCNT-I и SSCNT-II. Сопротивления этих пленок были рассчитаны в рамках метода неравновесных функции Грина: для SSCNT-I эти значения равнялись 18.13 кОм в направлении Z и 42.74 кОм в направлении Y, для SSCNT-II - 65.86 кОм в направлении Z и 60.17 кОм в направлении Y. Лучшая проводимость 
структуры с суперячейками SSCNT-I вдоль обоих направлений может быть объяснена наличием в ней меньшего количества дефектов. В совокупности с лучшей энтальпией реакции и механической прочностью можно сделать вывод, что пленки, состоящие из SSCNT-I, больше подходят для применения в электронных устройствах. Расчеты показывают, что сопротивление пленок из углеродных нанотрубок (УНТ) с квадратными ячейками выше, чем сопротивление УНТ в 4-10 раз, однако их структура позволяет размещать электроды как в вертикальном, так и в горизонтальном направлениях, что может иметь решающее значение для их использования в устройствах нательной электроники.

Ключевые слова: углеродные нанотрубки, сети с квадратными ячейками, молекулярное моделирование, проводимость.

\section{Introduction}

In recent years, networks of carbon nanotubes (CNTs), consisting of $\mathrm{X}-, \mathrm{Y}-$, and T-shaped junctions, are attracting more and more attention in the field of nanotechnology. Earlier it was reported that such structures can be created by various chemical vapor deposition (CVD) methods, by welding of CNTs and by chemical reaction [1]. Each of these compounds has unique properties. Y-compounds exhibit a unique electrical conductivity: they have an asymmetric I - V characteristic (IVC) at branchpoints [2]. The dependence of IVC on temperature shows that the mechanism of conductivity in Y-SWCNT is determined by thermionic emission at temperatures above $100 \mathrm{~K}$ and tunneling at $T<100 \mathrm{~K}$. Interesting mechanical properties were discovered in X-compounds in the result of mathematical modeling [3]. It was established that the behavior of such structures under unaxial strain and shear deformation is determined by the location and orientation of the bonds at the junction. $\mathrm{X}$-junctions demonstrate anisotropic properties under shear deformation. T-junctions provide a unique structure that allows them to compare the quasi-zero-dimensional Q0D contact formed at the junction node with the quasione-dimensional Q1D contact formed between the semiconducting bar and the lithographically defined gold [4]. The above-mentioned unique properties of CNT networks allow them to be used in the design of various devices. Choi et al. synthesized a Y-SWCNT network demonstrating a gating effect that indicates the similarity of its electrical characteristics to an ambipolar field-effect transistor [5]. A piezoelectric sensor based on CNT networks demonstrates excellent stability even after 3000 cycles of operation at $100 \%$ deformation [6]. It has been shown that CNT networks are a promising material for the manufacture of supercapacitors [7]. The high sensitivity of semiconductor CNT resistance to the addition of various impurities opens up new horizons for the development of highly sensitive biological and chemical sensors [8]. They can be used to recognize nerve agents [9], glucose and hydrogen peroxide [10].

Among a very large number of CNT networks, there is a separate class that can be called "supernetworks": in these structures the $\mathrm{C}-\mathrm{C}$ bond is replaced by CNT. There are many works that study such structures at the atomic level by mathematical modeling methods. In 2007, Romohera et al. identified 4 types of topological options for the formation of single-walled CNT networks: super-square CNT (SSCNT) and super-graphene CNT refer to 2D networks, while super-cubic CNT and super-diamond CNT are examples of $3 \mathrm{D}$ networks [11]. Of particular interest is the topological model of the 2D SSCNT lattice, which can be obtained as a result of the orthogonal X-shaped unit cell translation. Meng et al. [12] calculated the formation energy of the X-junction as a function of the crossed tube diameter by the molecular dynamics method based on the Brenner potential. This work for the first time established that the formation of an $\mathrm{X}$-junction is accompanied by the formation of pentagons, octagons and heptagons, the number of which depends on the chirality of isolated CNTs. Romocherra et al. [11] showed that the number of non-hexagonal elements in such compounds is completely determined by Euler's law in condition that three bonds for each carbon atom are retained. It was shown in the same manuscript that the conductivity of the 2D SS lattice is determined by the conductivity of CNT components. Orthogonal X-junctions formed by semiconductive CNTs (10.0) demonstrate a band gap about $0.8 \mathrm{eV}$, while orthogonal $\mathrm{X}$-compounds formed by metallic CNTs (6.6) retain metallic conductivity. Using molecular structural mechanics, it was found that the critical buckling forces decrease with the increasing pore length [13]. Sun et al. showed that 2D SSCNT meshes are promising as a water desalination membrane [14].

At the same time, there is no data on the numerical evaluation of the electrical conductivity of the 2D SSCNT networks, which could be used by technologists to develop electrical devices with vertical and horizontal orientation of the electrodes. In this regard, the goal of this work is to obtain the minimum possible dimensions of an SSCNT atomic supercell, to study its stress-strain state as well as to analyze the electrical conductivity of films composed of SSCNT supercells.

\section{SSCNT supercell model}

The SSCNT network unit cell was formed by four CNTs with lengths $L_{1}, L_{2}, L_{3}, L_{4}$ and diameter $D$, two graphene monolayers with a dimension of $m \times n$ (Fig. 1a, b,c) and free carbon atoms. To create a seamless junction, four CNTs, graphene layers and free carbon atoms were placed into a periodic box with translation vectors $L_{\mathrm{y}}=L_{1}+D+L_{4}$ and $L_{z}=L_{2}+D+L_{3}$ (red lines in Fig. 1a, b, c; the translation is carried out only in the $\mathrm{Y}$ and $\mathrm{Z}$ axes). The formation of an orthogonal $\mathrm{X}$-junction was performed within the force field AIREBO [15] at high temperatures. This process was simulated in the open source KVAZAR [16,17].

Self-assemblyoftheX-junction wasobserved:interatomic bonds were formed and broken while graphene layers were bent that led to the formation of defects in the place of contact between graphene and CNTs. It was considered armchair 


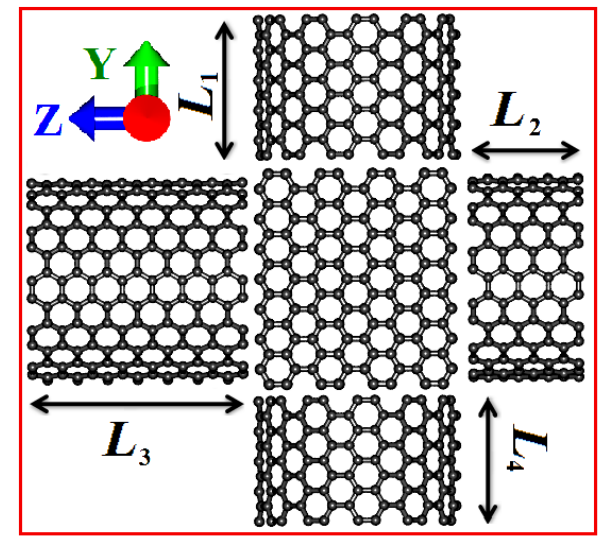

a

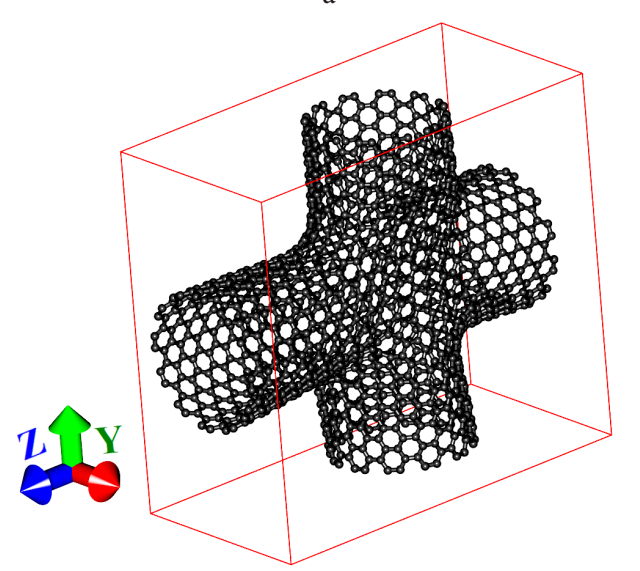

$\mathrm{b}$

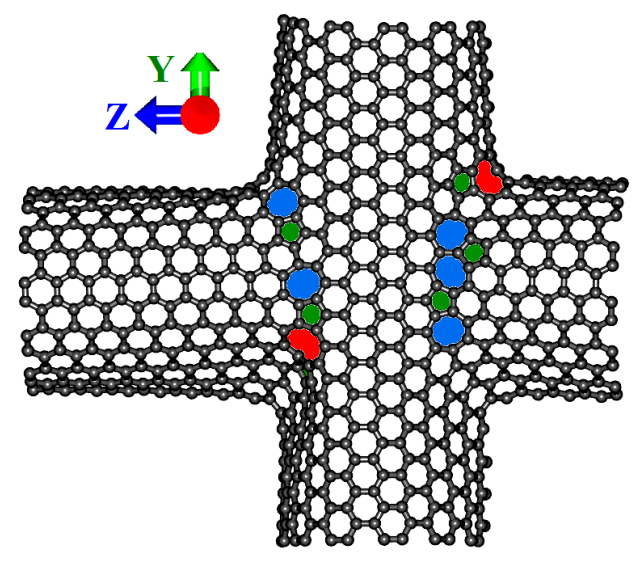

e
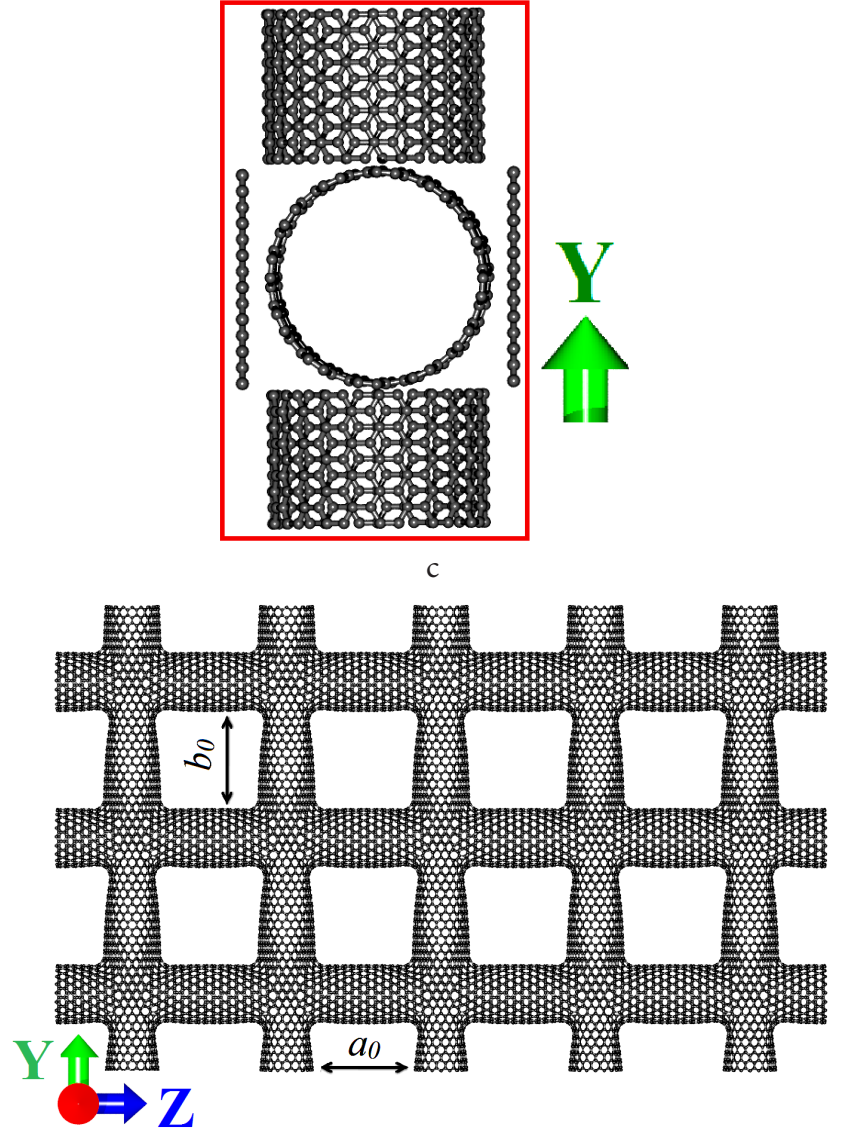

d

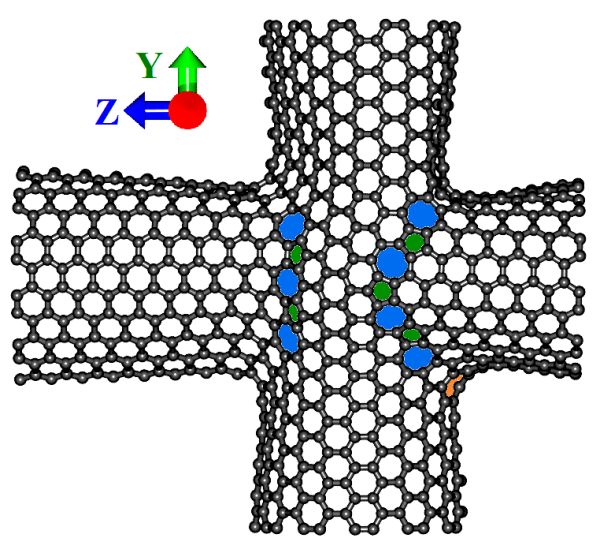

Fig. 1. (Color online) Supercells of SSCNT: components, required for the formation of an X-junction with a "window" $a_{0}=32.05 \AA$, $b=28.16 \AA$ : four carbon nanotubes, two graphene monolayers (main view). The red lines correspond to the periodic box (a); side view (b); $3 \mathrm{D}$-view (c); 2D network composed of SSCNT (d); supercell SSCNT-I (e); supercell SSCNT-II (f). The octagons are highlighted in orange, the heptagons are blue, the pentagons are green.

CNTs (12.12), since the diameter of such tubes $D=16 \AA$ corresponded to the most frequently synthesized ones [18]. Besides, these tubes exhibit metallic conductivity, so the networks of these CNTs will have higher electric conductivity. The lengths of the tubes $L_{1}, L_{2}, L_{3}, L_{4}$ ranged from 6.3 to $18.44 \AA$. The goal was to determine the smallest dimensions of the "window" $\left[a_{0}=L_{2}+L_{3}, b_{0}=L_{1}+L_{4}\right]$ that corresponded to the formation of an exothermic seamless X-junction (Fig. 1d). According to our research, the length and the width of such a "window" was $a_{0}=32.05 \AA$. $b_{0}=28.16 \AA$. Such configuration of the $\mathrm{X}$-junction was achieved when the lengths of the CNTs were $L_{1}=10.97 \AA, L_{2}=8.4 \AA, L_{3}=17.04 \AA$,
$L_{4}=9.78 \AA$, while the dimensions of monolayer graphene sheets $-m=15.62 \AA, n=14.6 \AA$. Also the formation of this junction required 23 carbon atoms.

Sufficient numerical experiments $(\sim 100)$ have shown that there are two types of $\mathrm{X}$-junction, which can be formed with such "window" dimensions. They differ in the number of non-hexagonal elements at the branchpoint (Fig. 1e,f). The SCC DFTB 2 method [19] and the software DFTB+ [20] were applied to refine the atomic structure of the obtained $\mathrm{X}$-junction and verify it senergy stability. A double re-optimization of atomic coordinates and translation vectors was performed. 
The heat of formation of theX-junctions was calculated by the following formula:

$$
\begin{aligned}
\Delta H & =E(\mathrm{X})-E(\mathrm{CNT} 1)-E(\mathrm{CNT} 2)-E(\mathrm{CNT} 3)- \\
& -E(\mathrm{CNT} 4)-23 E(\mathrm{C}),
\end{aligned}
$$

where $E(\mathrm{X})$ was the energy of the X-junction, $E(\mathrm{CNT} i)$ was the energy of the $i$-th CNT, $E(C)$ was the energy of the carbon atom.

As a result, two supercells, shown in Fig. 1e,f, were obtained. The X-junction in Fig. 1 will be called SSCNT-I. Its atomic mesh contains 12 pentagons, 20 heptagons and 2 octagons, the heat of formation is $-0.34 \mathrm{eV} /$ atom. Fig. If shows another structure, which is to be called SSCNT-II. It has 11 pentagons, 27 heptagons and 3 octagons. The heat of formation of this junction is higher $(-0.19 \mathrm{eV} /$ atom $)$, there are more defects in it. Note that the heat of formation values corresponds to the previously obtained data $(-0.275 \mathrm{eV} /$ atom for SSCNT (6.6) [11]). Bond lengths at the branchpoints are $1.398-1.482$ A for both junctions. Since both junctions are energetically stable, further we study the networks formed by supercells SSCNT-I and SSCNT-II.

Some mechanical and conductive properties were explored for the obtained models of SSCNT films.

\section{Mechanical properties}

As is well-known, for the application of materials in wearable electronics, it isimportant toknow theirbehavior understrain. To explore the stress-strain state of SSCNT films, the molecular dynamic method with the force field AIREBO was applied, which was previously successfully used to study the mechanical properties of the X-junction [21]. 2D-films were simulated by placing SSCNT-I and SSCNT-II into a periodic box $L_{\mathrm{y}}=L_{1}+D+L_{4}$ and $L_{\mathrm{z}}=L_{2}+D+L_{3}$. The structure was stretched by changing the sizes of the periodic box with a step of $0.01 \AA$ This step allows taking into account key phases of the stress-strain state. At each step, the structure was relaxed and its energy was calculated (Fig. 2). As it seen from Fig. 2, the dependence of energy on strain is linear at the initial stage (section OA) and is described by Hooke's law. In this ection, the deformation is reversible. For SSCNT-I the limit of proportionality is reached at a strain of $4.8 \%$, for SSCNT II $-4.2 \%$. Deformations in section $\mathrm{AB}$ can be approximated by a parabolic law. Point $B$ is the yield point, here the first destructions of chemical bonds are observed. For SSCNT-I, this point corresponds to a strain of $38.8 \%$, for SSCNT-II - 29.9\%. Earlier AFM and SGM measurement showed that SCNT withstands 30\% stretching without loss of mechanical strength and conductive properties [22]. Both structures are irreversibly destroyed upon further stretching. The maximum average stress, calculated as the ratio of the change in total energy per atom to the volume of the atom, is $0.18 \mathrm{MPa}$ for SSCNT-I and $0.15 \mathrm{MPa}$ for SSCNT-II. Thus, it can be concluded that films composed of SSCNT-I can withstand a higher load than films composed of SSCNT-II, films composed of SSCNT-I destruct at a lower strain.

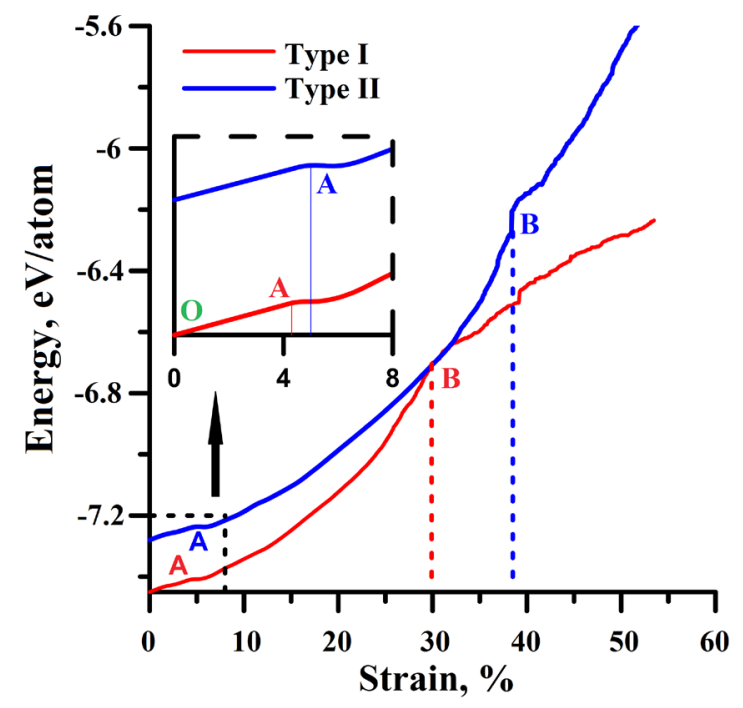

Fig. 2. (Color online) Stress-strain state for SSCNT-I and SSCNT-II films.

\section{Conductive properties}

The originally modified non-equilibrium Green function (NEGF) method with a density functional tight-binding (DFTB) scheme was used to calculate the transmission function of SSCNT supercells [23]. Tails of the CNTs were taken as left and right electrodes. The transmission function of the 2D SSCNT film was calculated for both types of supercells in the $\mathrm{Z}$ and $\mathrm{Y}$ directions (Fig. 3). It can be seen that near the Fermi level $(-4.64 \mathrm{eV})$, the values of the transmission function for SSCNT-I are higher than for SSCNT-II. It can be concluded that structure I is a better conductor than structure II. Based on the obtained T(E), the resistances of the 2D SSCNT network in two directions was calculated: for SSCNT-I, these values were $18.13 \mathrm{k} \Omega$ in the $\mathrm{Z}$ direction and $42.74 \mathrm{k} \Omega$ in the Y direction, for SSCNT-II $65.86 \mathrm{k} \Omega$ in the $\mathrm{Z}$ direction and $60.17 \mathrm{k} \Omega$ in the $\mathrm{Y}$ direction.

The next stage of the calculations is the transition from the supercells SSCNT to the $2 \mathrm{D}$ film. Let us calculate the resistance of the 2D SSCNT film shown in Fig. 4.

We assume that the electrodes are located on the left and right sides of the structure. Then the potential difference in the $Y$ direction will be zero, and the current will flow only in the $\mathrm{Z}$ direction. Thus, the $2 \mathrm{D}$ film from SSCNTs can be replaced by the equivalent scheme shown in Fig. 4. Let the 2D film contain $m \mathrm{X}$-junctions in the $\mathrm{Y}$ direction and $n$ $\mathrm{X}$-junctions in the $\mathrm{Z}$ direction. Then the resistance of each branch $R_{b}$, parallel to the $Z$ axis, will be equal to:

$$
R_{b}=m\left(R_{s p}+R_{\mathrm{CNT}}\right)
$$

where $R_{s p}$ is the resistance of the SSCNT supercell, $R_{\mathrm{CNT}}$ is the resistance of CNT.

It is known that charge transport through CNT less than $0.5 \mu \mathrm{m}$ in length is ballistic, so $R_{\mathrm{CNT}}$ within this range will be equal for nanotubes with equal diameters [24]. The resistance of the entire structure $R_{e q}$ will be equal to the resistance of $n$ parallel branches:

$$
R_{e q}=\frac{R}{n}=\frac{m}{n}\left(R_{s p}+R_{\mathrm{CNT}}\right) .
$$



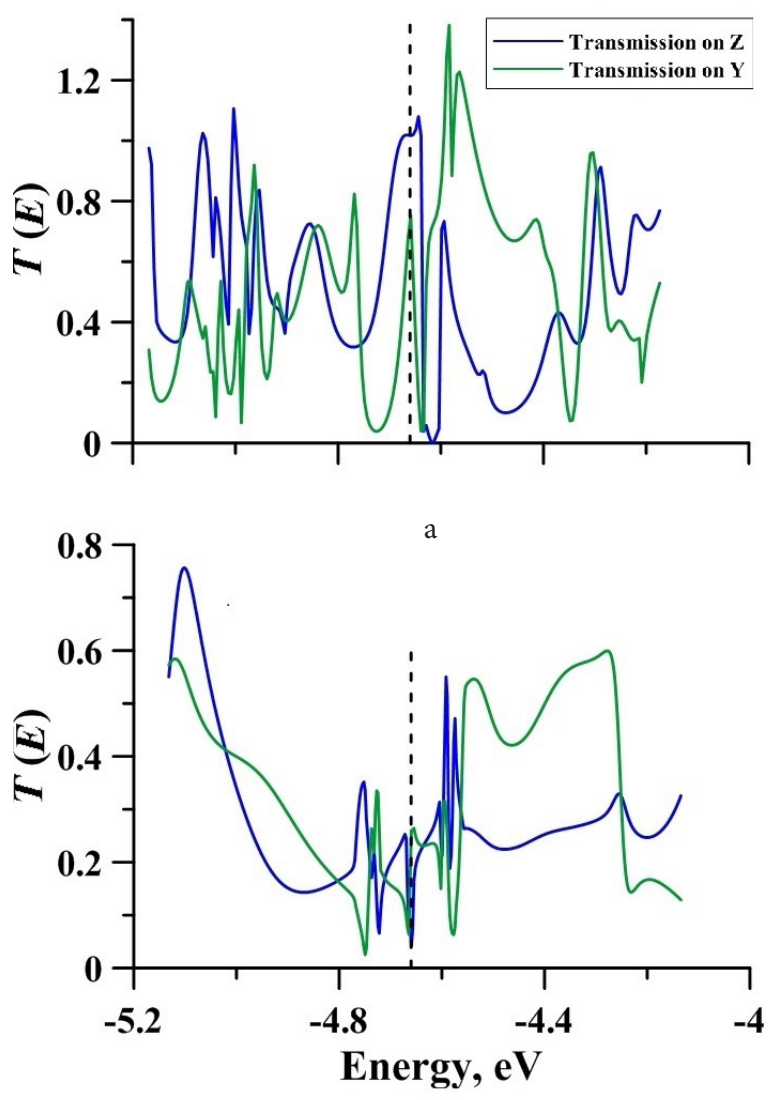

$b$

Fig.3. (Color online) The transmission function for supercells SSCNT-I and II in the Z (blue line) and Y (green line) directions: SSCNT-I (a); SSCNT-II (b).
For a 2D film with length $a$, width $b$ and "window dimension" $a_{0} \times b_{0}$ (Fig. 4) composed of CNT with diameter $D$, the total resistance can be calculated by the formula:

$$
R_{e q}=\frac{b}{D+b_{0}} \frac{D+a_{0}}{a}\left(R_{s p}+R_{\mathrm{CNT}}\right)
$$

Obviously, if the structure is a square, in which the dimensions of the "window" are equal to each other $(a=b$, $a_{0}=b_{0}$ ) then the resistance of such a structure will be equal to the resistance of the SSCNT supercell $\left(R=R_{s p}\right)$.

Let us calculate the resistance of $2 \mathrm{D}$ SSCNT films composed of SSCNT-I and SSCNT-II supercells. Let us consider a square structure $1 \times 1 \mathrm{~cm}^{2}$ with a pore size of $a_{0}=9 \mathrm{~nm}, b_{0}=7.2 \mathrm{~nm}$ from paper [25].Using formula (4), we will obtain the data from Table 1.

\section{Discussions}

Two possible supercells of the SSCNT structure with minimal sizes of the "window" were obtained in the result of mathematical modeling. These supercells, called SSCNT-I and SSCNT-II, are distinguished by their topology and the number of non-hexagonal elements. Based on the analysis of stress-strain state curves, it was established that the structure SSCNT-I with a smaller number of defects was stronger. It was calculated that the resistance of $2 \mathrm{D}$ films composed of the obtained supercells and the structure with supercells SSCNT-I had better conductivity along both directions due to the smaller number of defects.
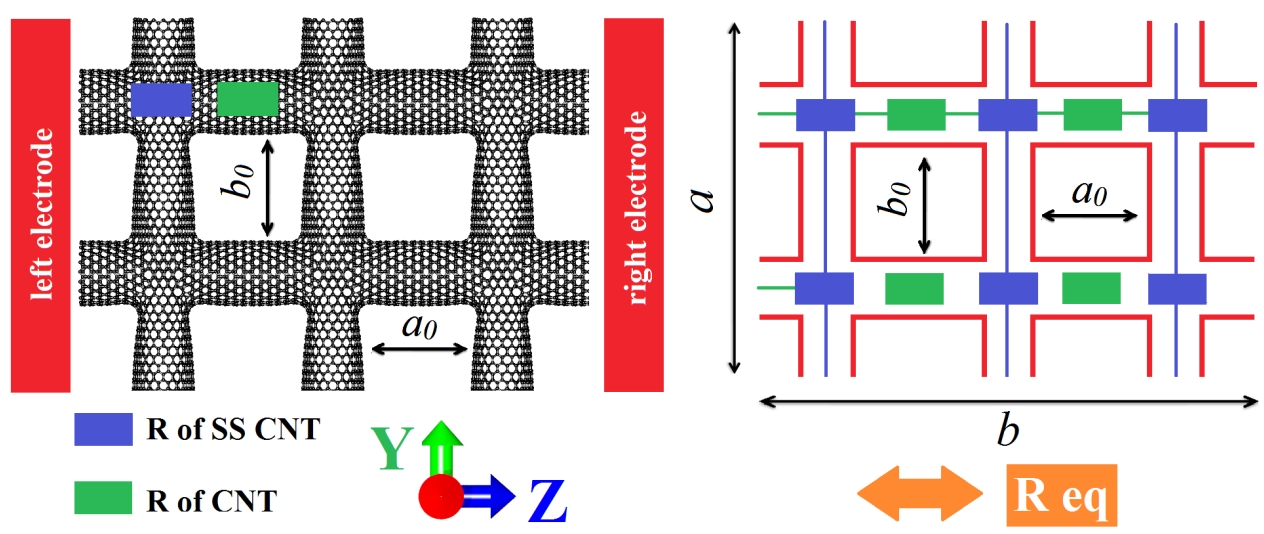

Fig. 4. (Color online) 2D SSCNT film with electrodes: atomic structure (left); equivalent scheme (right).

Table 1. Total resistance of 2D films composed of supercells SSCNT-I and SSCNT-II in the Z and Y directions.

\begin{tabular}{|c|c|c|c|c|c|c|c|}
\hline & $R_{s p}, \mathrm{k} \Omega$ & $R_{\mathrm{CNT}}, \mathrm{k} \Omega$ & $a=b, \mathrm{~cm}$ & $a_{0}, \mathrm{~nm}$ & $b_{0}, \mathrm{~nm}$ & $d, \mathrm{~nm}$ & $R_{e q} \mathrm{k} \Omega$ \\
\hline $\begin{array}{c}\text { SSCNT-I, } \\
\text { Z direction }\end{array}$ & 18.13 & 6.4 & 1 & 9 & 7.2 & 1.6 & 29.55 \\
\hline $\begin{array}{c}\text { SSCNT-I, } \\
\text { Y direction }\end{array}$ & 42.74 & 6.4 & 1 & 9 & 7.2 & 1.6 & 58.97 \\
\hline $\begin{array}{c}\text { SSCNT-II, } \\
\text { Z direction }\end{array}$ & 65.86 & 6.4 & 1 & 9 & 7.2 & 1.6 & 86.712 \\
\hline $\begin{array}{c}\text { SSCNT-II, } \\
\text { Y direction }\end{array}$ & 60.17 & 6.4 & 1 & 9 & 7.2 & 1.6 & 79.88 \\
\hline
\end{tabular}


Togetherwith thelowerheat of formation and mechanical strength, it can be concluded that films composed of SSCNT-I are more suitable for application in electronic devices. Calculations show that the resistance of SSCNT films is higher than the resistance of CNT in 4-10 times, but they allow placing electrodes in both vertical and horizontal directions that can be crucial for wearable electronics. Another suitable application of these SSCNTs is ten so resistive materials for sensors [26]. To continue work in this field, it is necessary to calculate the dependence of such structure resistance on temperature.

\section{References}

1. D. Wei, Y.Liu. Adv. Mater. 20, 2815-2841 (2008). DOI: 10.1002/adma.200800589

2. L.P. Biro, Z.E. Horvath, G.I. Mark et al. Diam. Relat. Mater. 13, 241 (2004). DOI: $10.1016 /$ j.diamond.2003.10.014

3. B. A. Stormer, N.M. Piper, X.M. Yang et al. Inter. Jour. Smart Nano Mat. 3 (1), 33 (2012). DOI: $10.1080 / 19475411.2011 .640361$

4. P. W. Chiu and S. Roth. Appl. Phys. Lett. 91, 102109 (2007). DOI: 10.1063/1.2780076

5. W. Choi, D. Kim, Y. C. Choi et al. JOM. 59, 44 (2007). DOI: $10.1007 / \mathrm{s} 11837-007-0038-\mathrm{Z}$

6. D. J. Cohen, D. Mitra, K. Peterson et al. Nano Lett. 12 (4), 1821 (2012). DOI: 10.1021/nl204052z

7. B. You, J. Jiang, S. Fan. ACS Appl. Mater. Interfaces. 6 (17), 15302 - 8 (2014). DOI: 10.1021/am503783t

8. C. Li, M. Curreli, H. Lin et al. J. Am. Chem. Soc. 127 (36), 12484 (2005). DOI: 10.1021/ja053761g

9. J. P. Novak, E.S. Snow, E. J. Houser et al. Appl. Phys. Lett. 83 (19), 4026 (2003). DOI: 10.1063/1.1626265

10. J. C. Claussen, A. D. Franklin, A. ul Haque et al. ACS Nano. 3 (1), 37 (2009). DOI: 10.1021/nn800682m

11. J. M. Romo-Herrera, M. Terrones, H. Terrone et al.
Nano lett. 7 (3), 570 (2007). DOI: 10.1021/nl0622202

12. F. Y. Meng, S. Q. Shi, D.S. Xu, R. Yang. Carbon. 44 (2006) 1263-1266. DOI: 10.1016/j.carbon.2005.10.049

13. L. Ying, Q. XinMing, Y. Yajun. Phys. Let. A. 374, 1773 (2010). DOI: 10.1016/j.physleta.2010.02.033

14. L. Sun, X. He, J. Lu Comp. Mat. 2, 16004 (2016). DOI: $10.1038 /$ npjcompumats.2016.4

15. D. W. Brenner, O.A. Shenderova, O.A. Harrison et al. J. Phys.: Condens. Matter. 14 (4), 783 (2002). DOI: $10.1088 / 0953-8984 / 14 / 4 / 312$

16. O.E. Glukhova. Molecular Dynamics as the Tool for Investigation of Carbon Nanostructures Properties. In: Thermal Transport in Carbon-Based Nanomaterials. Ed. by Gang Zhang. 1st Edition. Imprint: Elsevier (2017) P. $267-290$.

17. http://nanokvazar.ru/

18. M. Tavakkoli, T. Kallio, O. Reynaud et al. J. Mater. Chem. A. 4, 5216 (2016). DOI: 10.1039/c6ta01472k

19. M. Elstner, D. Porezag, G. Jungnickel et al. Phys. Rev. B. 56, 7260 (1998). DOI: 10.1103/PhysRevB.58.7260

20. http://www.dftb.org/

21. B. A. Stormer, N. M. Piper, X. M. Yang et al. International Journal of Smart and Nano Materials. 3 (1), 33 (2012). DOI: 10.1080/19475411.2011.640361

22. D. Bozovic and M. Bockrath. Phys. Rev. B. 67, 033407 (2003). DOI: 10.1103/PhysRevB.67.033407

23. O. E. Glukhova, D. S. Shmygin. Beilstein J. Nanotechnol. 9, 1254 (2018). DOI: 10.3762/bjnano.9.117

24. M. J. Biercuk, S. Ilani, C. M. Marcus, and P. L. McEuen. In Carbon Nanotubes. Topics in Applied Physics (Eds. Dresselhaus and Dresselhaus) 111 (2008), 455 p.

25. X. Gui, J. Wei, K. Wang et al. Adv. Mater. 22, 617 (2010) DOI: 0.1002/adma.200902986

26. L. P. Ichkitidze, A. Yu. Gerasimenko, V. M. Podgaetsky, S. V. Selishchev. Mat. Phys. and Mech., 37 (2), $153-158$ (2018). DOI: 10.18720/MPM.3722018_7 